\title{
New paradigms in cervical cancer prevention: opportunities and
} risks

\author{
Guglielmo Ronco*1 and Paolo Giorgi Rossi²
}

\author{
Address: ${ }^{1}$ Unità di Epidemiologia dei Tumori, CPO Piemonte, Torino, Italy and ${ }^{2}$ Laziosanità - Agenzia di Sanità Pubblica, Regione Lazio, Roma, \\ Italy \\ Email: Guglielmo Ronco* - guglielmo.ronco@cpo.it; Paolo Giorgi Rossi - giorgirossi@asplazio.it \\ * Corresponding author
}

Published: 17 December 2008

BMC Women's Health 2008, 8:23 doi:10.1 I86/1472-6874-8-23

This article is available from: http://www.biomedcentral.com/l472-6874/8/23

(c) 2008 Ronco and Rossi; licensee BioMed Central Ltd.

This is an Open Access article distributed under the terms of the Creative Commons Attribution License (http://creativecommons.org/licenses/by/2.0), which permits unrestricted use, distribution, and reproduction in any medium, provided the original work is properly cited.

\begin{abstract}
Testing for the DNA of high-risk types of papilloma virus (HPV) is more sensitive than cytology in detecting pre-cancerous lesions. One of the main advantages will be the possibility of applying prolonged screening intervals. However adequate screening protocols (age of start and stop, screening intervals, management of HPV positive women) need to be applied in order to avoid over-referral to colposcopy and over-treatment and to maintain sustainable costs. Further followup of running trials and research on molecular markers will better define these parameters. The new situation will require organised screening programmes with rigorous protocols and monitoring. This will be even more needed when women vaccinated for HPV 16 and 18 will be screened. Research on how to best screen vaccinated women is a priority. This paper proposes an overview of the plausible impact of new technologies in cervical cancer screening in the near future and in the vaccinated cohorts.
\end{abstract}

\section{Background \\ Human Papilloma virus (HPV) as primary screening test of cervical cancer precursors}

Both studies based on double-testing of the same women $[1,2]$ and large population trials [3-8] showed that testing for the DNA of high-risk HPV types is more sensitive but less specific than conventional cytology in identifying high-grade cervical intraepithelial neoplasia (CIN).

HPV testing detects almost all high-grade CINs identified by cytology $[1,2]$. As a result, almost the same sensitivity is obtained with HPV alone as with both cytology and HPV together as primary screening tests (i.e. if only HPVpositive or also HPV-negative women with abnormal cytology are referred to colposcopy). However, with the combined strategy, referrals to colposcopy are much more frequent and the probability that test-positive women actually have a high-grade CIN (the Positive Predictive Value, PPV) is substantially lower $[3,4]$.

In women at least 35 years of age, in the "New Technology in Cervical Cancer" (NTCC) trial, HPV testing was found to be $63 \%$ more sensitive than cytology when all HPVpositive women are referred to colposcopy [8]. At this age loss in specificity is small: in a pooled analysis of European and North American studies based on double-testing [1], specificity was $93.3 \%$ with HPV DNA testing vs. $97.1 \%$ with cytology. However, even with HPV alone there is a remarkable loss in PPV. In the NTCC trial the relative ratio in PPV between HPV and cytology (relative PPV) was 0.67 [8].

Thus, a number of strategies to increase specificity have been or are being evaluated. The most studied strategy - 
that we will refer to as "cytological triage" - involves directly referring to colposcopy only HPV-positive women who also show cytological abnormalities, while the remaining HPV-positives are retested at shorter interval and referred to colposcopy only if they retest as HPV positive [9]. This approach is based on knowledge that only persistent HPV infections are relevant to carcinogenesis. Trials based on combined HPV and cytology screening but with cytological triage of HPV-positive women at least 30 (POBASCAM [6]) or 35 (Sweedscreen [7]) years of age found sensitivities about $50 \%$ higher than with cytology alone, very similar to those obtained when all HPV positive women are referred.

The persistence of lesions detected by HPV testing versus cytology is also a relevant factor. Remarkably, the two aforementioned studies [6,7] showed that HPV testing allowed an earlier detection of persistent, therefore clinically relevant, lesions. It is plausible that both age and the application of triage had a role in such a result. The observed earlier diagnosis means that the intervals for rescreening HPV-negative women can be longer. The very low detection rate of high-grade CIN at subsequent screening in previously HPV-negative women supports this choice. Longer intervals have the clear advantage of fewer screening episodes over a lifetime and may provide the opportunity of achieving higher coverage. Further follow-up of randomised trials will provide evidence on how long HPV screening intervals can be [10].

However, cytological triage requires that some women are re-tested at short intervals, which is a disadvantage because compliance rarely is complete. Other strategies, based on molecular markers, are under study. These include viral load, genotyping, testing for the RNA of the viral oncogenes E6 and E7 and testing for the over-expression of the p16-INK4A protein [11]. Recently HPV testing with a single immediate triage test for p16-INK4A overexpression - with no further recall - showed a relative sensitivity of 1.53 with virtually no increase in referrals to colposcopy (relative referral 1.08) [12].

Among younger women the situation is slightly more complicated. At this age infection is very frequent and HPV test specificity is lower. Nevertheless, among women 25-34 years of age, in the NTCC trial, HPV testing with cytological triage resulted in a relative sensitivity vs. cytology of 1.58 with only a moderate loss in PPV (relative PPV 0.78 ) [4]. However, a major problem at this age is overdiagnosis. Data from the NTCC study, involving direct referral of all HPV positive women, found a very large increase in sensitivity (relative sensitivity 3.50) suggesting that a large proportion of the lesions detected by this strategy at this age are regressive. Results from the follow-up of the NTCC study, currently under analysis, will provide information on the appropriateness of HPV screening at younger ages.

\section{Conclusion}

In conclusion, available results strongly support the adoption of HPV testing for cervical screening. However, before general routine implementation, the follow-up results of running randomised trials, which will be available soon, should be considered. They will also provide evidence on some aspects that need to be better defined: age at first testing, the best screening interval, the best management of HPV positive women. In the meantime, starting large pilot (demonstration) projects seems reasonable. This will allow us to estimate the impact of the application of new technologies in practice, evaluate costs (to date the major barrier to using HPV as the primary test is the price of the kit [13]) and set up systems for quality assurance and monitoring.

In any case, the following issues must be taken into account:

- Applying longer screening intervals represents a major advantage of HPV testing. This is also needed in order to maintain sustainable costs.

- Adequate protocols need to be applied. In their absence there is a risk not only of over-referral to colposcopy but also of overtreatment (see the case of direct referral to colposcopy of younger HPV positive women), and therefore for potential harm (excisional treatment for CIN increases the risk of complications in pregnancy $[14,15])$.

- Validated tests with appropriate sensitivity and more importantly, specificity must be adopted

All of these factors indicate the need for organised screening programmes that actively invite women at the appropriate intervals, adopt well-defined management protocols, register all results (the application of protocols requires accurate knowledge of women's screening experience) and monitor performances.

\section{New scenario in the vaccine era}

Two vaccines - one against the oncogenic HPV types 16 and 18 and one that also includes the non-oncogenic types 6 and 11 - proved to be highly effective in preventing HPV16/18-linked CIN2+ $[16,17]$. In some countries vaccination is free of charge or actively offered to adolescents [18]. There is large consensus that vaccinated women need screening [19-21], as HPV 16 and 18 are only responsible for $75 \%$ of cervical cancers. We must understand how vaccinated women should best be screened. In vaccinated women the incidence of CIN2+ is expected to be reduced by $50-60 \%$ compared to the 
unvaccinated but vaccination reduces the incidence of low grade CIN and ASC-US only by $20 \%$ [22]. Thus, with cytology, the detection rate will decrease much more than referrals to colposcopy. Consequently PPV will substantially decrease. However, as non-16/18 HPV types have a lower probability of neoplastic progression, the PPV of HPV testing will also decrease in vaccinated women.

Overall, this scenario represents an additional reason for shifting to HPV testing but will require even more conservative protocols, to achieve high PPV for colposcopy referral, both in order to avoid false positive histological diagnoses (that are inversely related to the PPV of referral [23]) and to maintain sustainable overall costs of cervical cancer control. The lower incidence of high-grade CIN with non-16/18 HPV types [24] - therefore the longer interval between infection and the development of such lesions - suggests the possibility of even longer screening intervals. Research on this subject is a priority. In any case, this situation will need a coordinated program for cervical cancer prevention that will be able to integrate vaccinations and screening, ensuring appropriate prevention to all women throughout their life, according to their history of immunisation and screening.

\section{Abbreviations}

HPV: Human Papilloma Virus; NTCC: New Technology in Cervical Cancer, multicentre randomised trial; CIN: Cervical Intraepitelial Neoplasia; CIN2+: Cervical Intraepitelial Neoplasia grade 2 or more severe; PPV: Positive Predictive Value.

\section{Competing interests}

GR received minor payment by GenProbe for participating in internal scientific advisory boards. The Agency for Public Health received a grant by Sanofi Pasteur MSD for a study on the HPV-related burden of disease in Italy. PGR received travel reimbursement to present the results of the study at two international conferences and at an internal workshop.

\section{Authors' contributions}

GR drafted the section on HPV testing for primary screening and PGR the section on the new scenario in the vaccine era. Both authors discussed the entire text and approved the final manuscript.

\section{Acknowledgements}

We want to thank all the researchers, physicians, midwives, public health professionals and women that contributed to the NTCC trial carrying out. We also thank Margaret Becker for the English editing.

\section{References}

I. Cuzick J, Clavel C, Petry KU, Meijer CJL, Hoyer H, Ratnam S, Szarewski $A$, Birembaut $P$, Kulasingam S, Sasieni $P$, Iftner $T$ : Overview of the European and north American studies on HPV testing in primary cervical screening. Int J Cancer 2006, I I 9:1095-101.
2. Cuzick J, Arbyn M, Sankaranarayanan R, Tsu V, Ronco G, Mayrand $\mathrm{MH}$, Dillner J, Meijer CJL: Overview of human papillomavirusbased and other novel options for cervical cancer screening in developed and developing countries. Vaccine 2008, 26S:K29-K4I.

3. Ronco G, Segnan N, Giorgi-Rossi P, Zappa M, Casadei GP, Carozzi F, Dalla Palma P, Del Mistro A, Folicaldi S, Gillio-Tos A, Nardo G, Naldoni C, Schincaglia P, Zorzi M, Confortini M, Cuzick J, the NTCC Working Group: Human Papillomavirus testing and liquidbased cytology in primary cervical screening: results at recruitment from the NTCC randomized controlled trial. J Natl Cancer Inst 2006, 98:765-74.

4. Ronco G, Giorgi-Rossi P, Carozzi F, Dalla Palma P, Del Mistro A, De Marco A, De Lillo M, Naldoni C, Pienotti P, Rizzolo R, Segnan N, Schincaglia P, Zorzi M, Confortini M, Cuzick J, the NTCC Working Group: Human papillomavirus testing and liquid-based cytology in primary screening among younger women: results at recruitment from the NTCC randomised controlled trial. Lancet Oncol 2006, 7:547-55.

5. Mayrand MH, Duarte-Franco E, Rodrigues I, Walter SD, Hanley J, Ferenczy A, Ratnam S, Coutlée F, Franco EL, for the Canadian Cervical Cancer Screening Trial Study Group: Human papillomavirus DNA versus Papanicolau screening tests for cervical cancer. New Engl J Med 2007, 357: 1 579-88.

6. Bulkmans NW, Berkhof J, Rozendaal L, van Kemenade FJ, Boeke AJ, Bulk S, Voorhorst FJ, Verheijen RH, van Groningen K, Boon ME, Ruitinga W, van Ballegooijen M, Snijders PJ, Meijer CJ: Human papillomavirus DNA testing for the detection of cervical intraepithelial neoplasia grade 3 and cancer: 5-year follow-up of a randomised controlled implementation trial. Lancet 2007, 370: $1764-72$.

7. Naucler P, Ryd W, Törnberg S, Strand A, Wadell G, Elfgren K, Rådberg T, Strander B, Forslund O, Hansson BG, Rylander E, Dillner J: Human papillomavirus and Papanicolaou tests to screen for cervical cancer. N Engl J Med 2007, 357:1589-97.

8. Ronco G, Giorgi-Rossi P, Carozzi F, Confortini M, Dalla Palma P, Del Mistro A, Gillio-Tos A, Minucci D, Naldoni C, Rizzolo R, Schincaglia P, Volante R, Zappa M, Zorzi M, Cuzick J, Segnan N, the NTCC Working Group: Results at Recruitment from a Randomized Controlled Trial Comparing Human Papillomavirus Testing Alone to Conventional Cytology as the Primary Cervical Cancer Screening Test. J Natl Cancer Inst 2008, 100:492-50I.

9. Cuzick J, Szarewski A, Cubie H, Hulman G, Kitchener H, Luesley D, McGoogan E, Menon U, Terry G, Edwards R, Brooks C, Desai M, Gie C, Ho L, Jacobs I, Pickles C, Sasieni P: Management of women who test positive for high-risk types of human papillomavirus: the HART study. Lancet 2003, 362:187|-1876.

10. Ronco G, Segnan N: Human papillomavirus testing for primary cervical cancer screening (invited comment). Lancet 2007, 370:1740-1742.

II. Cuzick J, Mayrand MH, Ronco G, Snijders P, Wardle J: Chapter I0: New dimensions in cervical cancer screening. Vaccine 2006, 24(Suppl 3):S90-7.

12. Carozzi F, Confortini M, Dalla Palma P, Del Mistro A, Gillio-Tos A, De Marco L, Giorgi-Rossi P, Ponentani G, Rosso S, Sani C, Sintoni C, Segnan N, Cuzick J, Rizzolo R, Ronco G, the New Technologies for Cervical Cancer screening (NTCC) working group: Use of p I 6INK4A overexpression to increase the specificity of human papillomavirus testing: a nested substudy of the NTCC randomised controlled trial. Lancet Oncol 2008, 9:937-45.

13. Giorgi Rossi P, Segnan N, Zappa M, Naldoni C, Zorzi M, Confortini M, Merito M, Ronco G, the NTCC Working Group: The impact of new technologies in cervical cancer screening: results of the recruitment phase of a large randomised controlled trial from a public health perspective. Int J Cancer 2007, | 2 | :2729-2734.

14. Arbyn M, Kyrgiou M, Simoens C, Raifu Ao, Koilopulos G, Martin-Hirsch P, Prendiville W, Paraskevaidis E: Perinatal mortality and other severe adverse pregnancy outcomes associated with treatment of cervical intraepithelial neoplasia: meta analysis. BMJ 2008, 337:a 1284.

15. Albrechtsen S, Rasmussen S, Thoresen S, Irgens LM, Iversen OE: Pregnancy outcome in women before and after conisation: population based cohort study. BMJ 2008, 337:a I 343. 
16. Future II Study Group: Quadrivalent vaccine against human papillomavirus to prevent high-grade cervical lesions. N Eng J Med 2007, 356:1915-27.

17. Paavonen J, Jenkins D, Bosch FX, Naud P, Salmerón J, Wheeler CM, Chow SN, Apter DL, Kitchener HC, Castellsague X, de Carvalho NS, Skinner SR, Harper DM, Hedrick JA, Jaisamrarn U, Limson GA, Dionne M, Quint W, Spiessens B, Peeters P, Struyf F, Wieting SL, Lehtinen MO, Dubin G, HPV PATRICIA study group: Efficacy of a prophylactic adjuvanted bivalent $L I$ virus-like-particle vaccine against infection with human papillomavirus types 16 and 18 in young women: an interim analysis of a phase III double-blind randomised controlled trial. Lancet 2007. 369(9580):216I-2170.

18. King LA, Levy-Bruhl D, O'Flanagan D, Bacci S, Lopalco PL, Kudjawu Y, Salmaso S, VENICE country-specific gate keepers and contact points: Introduction of human papillomavirus into national immunisation schedules in Europe: results of the VENICE 2007 survey. Euro Surveill 2008, I3(33):pii: 18954.

19. Bosch FX, Castellsagué X, de Sanjosé S: HPV and cervical cancer: screening or vaccination? $\mathrm{Br} /$ Cancer 2008, 98:|5-2|

20. Kiviat NB, Hawes SE, Feng Q: Screening for cervical cancer in the era of the HPV vaccine -the urgent need for both new screening guidelines and new biomarkers. I Natl Cancer Inst 2008, 100:290-I.

21. Schiffman M, Castle PE, Jeronimo J, Rodriguez AC, Wacholder S: Human papillomavirus and cervical cancer. Lancet 2007 370:890-907.

22. Clifford G, Franceschi S, Diaz M, Munoz N, Villa LL: Chapter 3: HPV type-distribution in women with and without cervical neoplastic diseases. Vaccine 2006, 24(Suppl 3):S26-34.

23. Dalla Palma P, Giorgi Rossi P, Collina G, Buccoliero AM, Ghiringhello B, Lestani M, Onnis GL, Aldovini D, Galanti G, Casadei GP, Aldi M. Gomes V, Giubilato P, Ronco G, the NTCC Pathology Group: The risk of false-positive histology according to the reason for colposcopy referral in cervical cancer screening: a blind revision of all histological lesions found in the NTCC trial. Am J Clin Pathol 2008, I 29:75-80.

24. Khan MJ, Castle PE, Lorincz AT, Wacholder S, Sherman M, Scott DR, Rush BB, Glass AG, Schiffman M: The elevated 10 -year risk of cervical precancer and cancer in women with human papillomavirus (HPV) type 16 or 18 and the possible utility of type-specific HPV testing in clinical practice. J Natl Cancer Inst 2005, 97:1072-9.

\section{Pre-publication history}

The pre-publication history for this paper can be accessed here:

http://www.biomedcentral.com/1472-6874/8/23/prepub
Publish with Bio Med Central and every scientist can read your work free of charge

"BioMed Central will be the most significant development for disseminating the results of biomedical research in our lifetime. "

Sir Paul Nurse, Cancer Research UK

Your research papers will be:

- available free of charge to the entire biomedical community

- peer reviewed and published immediately upon acceptance

- cited in PubMed and archived on PubMed Central

- yours - you keep the copyright
BioMedcentral 